\title{
Haematological abnormalities in human immunodeficiency virus (HIV) disease
}

\author{
CHRISTINE COSTELLO \\ From the Department of Haematology, St Stephen's Hospital, London
}

Peripheral blood and bone marrow changes are commonly seen in disease associated with human immunodeficiency virus (HIV). This annotation aims to summarise these changes and to suggest possible factors entailed in their occurrence.

The wideranging clinical and pathological changes in patients infected with HIV virus are both fascinating and challenging to physicians and pathologists alike. Haematological abnormalities are well recognised in HIV disease and result from diverse influences on the haemopoietic tissue. Changes in the peripheral blood and bone marrow may reflect disease elsewhere in the body, may result from treatment for that disease, may reflect an attempt to attack the HIV virus itself, or may seem to be isolated haematological disorders. Only by monitoring blood changes and correlating them with the clinical state of the patient can we hope to understand the mechanisms involved and to suggest what their clinical importance might be.

\section{Peripheral blood changes}

Leucopenia is common in patients with HIV infection and seems to correlate with the severity of the disease. Two hundred and twelve $(23 \%)$ of a series of $925 \mathrm{HIV}$ antibody positive patients at this hospital were leucopenic at some stage during their illness, and $88 \%$ of patients with acquired immune deficiency syndrome (AIDS) or AIDS-related complex (ARC) were leucopenic at presentation. ' Of interest is the contribution of lymphopenia, neutropenia, and granulocytopenia to the reduction of total number of white cells.

Lymphopenia in HIV disease is common, cells of the $T$ helper phenotype being specifically depleted. In patients with AIDS and opportunistic infections immune function is more severely disturbed than in

Accepted for publication 3 March 1988 patients with AIDS and opportunistic tumours. ${ }^{2}$ Care must be taken when interpreting the ratio of $T$ helper to $\mathrm{T}$ suppressor cells. Only when there is lymphopenia does a decreased ratio indicate depletion of $T$ helper cells. In patients with a normal lymphocyte count a decreased ratio might result either from $\mathrm{T}$ helper cell depletion or from $\mathrm{T}$ suppressor cell increase.

Mir found a $79 \%$ incidence of lymphopenia in $\mathbf{4 0}$ patients with AIDS and in our series of 925 HIV antibody positive patients studied during 1987, 305 (33\%) were lymphopenic; most of these patients had AIDS or ARC. ${ }^{3}$

Granulocytopenia is a less well recognised feature of HIV disease but was seen in $185(20 \%)$ of 925 HIV antibody positive patients (Haematological features of HIV disease, Costello C, unpublished observations). In Treacy's series two thirds of the patients with AIDS or ARC having bone marrow examinations were granulocytopenic ${ }^{l}$ and this figure was similar in a larger series of 60 patients at St Stephen's Hospital undergoing bone marrow examinations (Proceedings of meeting on prospective indications for intravenous immunoglobulin, 1988). ${ }^{3}$

A left shift in the granulocytic series is a common finding ${ }^{14}$ and may reflect the clinical condition of the patient. The pathogenesis of neutropenia is obscure, though several factors are likely to be important: concurrent infections, drugs which suppress the marrow, and probably, in some cases, an immune process. Murphy et al studied 105 HIV antibody positive patients and found neutropenia in $20 \%$ of patients with AIDS, $25 \%$ of patients with persistent generalised lymphadenopathy (PGL), but none of 26 asymptomatic HIV antibody positive subjects. ${ }^{5} \mathrm{He}$ performed granulocyte immunofluorescence tests (GIFT) on 34 HIV antibody positive men, two with AIDS, 24 with PGL, and eight who were asymptomatic. Seven of the 34 were neutropenic and in four the GIFT reaction was positive. Six patients with normal neutrophil counts also showed positive GIFT 
tests but in none of these patients with positive reactions was there any correlation with concentrations of circulating immune complexes. Thus in at least some patients with neutropenia an autoimmune mechanism might be implicated.

Van der Lehe also found granulocyte bound immunoglobulin in patients with HIV disease and to a lesser extent in high risk patients without evidence of HIV disease. ${ }^{6}$ In some cases acid eluates from the granulocytes contained immunoglobulins reacting with normal granulocytes, thus indicating that they were autoantibodies rather than non-specifically bound immune complexes. Presumably the immune imbalance in HIV infected patients may result in the production of autoantibodies to blood cells.

An alternative cause for the neutropenia seen in patients with HIV disease might be decreased bone marrow production of granulocytes consequent on inhibition of granulocyte progenitors. Leiderman et al described deficiency of growth of the granulocytemacrophage progenitor cell (CFU-GM) from bone marrows of patients with HIV disease and postulated that a glycoprotein present in the marrow of infected patients might be the inhibitory agent. ${ }^{7}$

Monocytopenia was apparent in $79(8.6 \%)$ of the 925 HIV antibody positive patients studied by Costello and in a higher percentage of patients from whom marrow aspirates were taken $(35 \%$ of Treacy's series, $43 \%$ of Mir's patients). Morphological abnormalities of monocytes were observed by Treacy and also by Spivak, ${ }^{4}$ the monocytes showing cytoplasmic vacuolisation and abnormal nuclear features.

Anaemia is commonly seen in patients with AIDS, ${ }^{148}$ often reflecting reticuloendothelial iron block and effects of treatment with drugs such as co-trimoxazole, pentamidine, foscarnet and more recently zidovudine (AZT). Blood transfusion is often necessary in patients with AIDS, especially in those receiving AZT, a drug which produces severe anaemia in a proportion of recipients. ${ }^{9}$ Forty nine $(36 \%)$ of 138 patients treated with AZT at this hospital required blood transfusion at least once. ${ }^{10}$

Erythroid hypoplasia with severe anaemia has recently been described in patients with disseminated Mycobacterium avium-intracellulae (MAI) infection."

Whether bone marrow stem cells are infected with the HIV virus is as yet unknown but Zon suggested that erythropoiesis could be suppressed by the action of the retrovirus on progenitor cell proliferation or maturation. ${ }^{8}$ Spivak raised the possibility of the anaemia in HIV disease being at least partly the result of suppression of erythropoiesis by cell to cell interaction. ${ }^{4}$ The imbalance of $\mathrm{T}$ helper and $\mathrm{T}$ suppressor cell populations in AIDS lends credence to this theory.

Thrombocytopenia is a well recognised occurrence in patients infected with the HIV virus. It may be immune in aetiology, related to drugs, or part of the pancytopenia often seen in ill patients with opportunistic infections.

The incidence of thrombocytopenia has perhaps not been fully appreciated. The initial reluctance to put samples through a whole blood counter led to an evaluation of platelet numbers often being made on a blood film. Mild degrees of thrombocytopenia were quite likely overlooked. At this hospital we found a $13 \%$ incidence of thrombocytopenia (121 of 925 patients studied over 12 months) in patients who were at risk for HIV disease. Although most of the patients had either AIDS or ARC, $12 \%$ of the patients with thrombocytopenia were HIV antibody positive, and asymptomatic.

The diagnosis of immune thrombocytopenia is often made on clinical and bone marrow findings as platelet-associated immunoglobulin testing has not been widely used in high risk patients for reasons of safety. In patients with reduced platelet numbers and no splenomegaly, no drug treatment, and a marrow showing plentiful megakaryocytes, a presumptive diagnosis of immune thrombocytopenia may be made. The condition varies in HIV antibody positive patients, as in other patients with immune thrombocytopenia, from a well compensated state with only a mild reduction in platelet numbers to a severe condition with very low platelet counts.

The mechanism for immune thrombocytopenia has been studied by several workers in the United States. Walsh et al showed high concentrations of plateletassociated IgG and complement in homosexual patients with idiopathic thrombocytopenia (ITP). ${ }^{12}$ These values were around four times higher than those seen in classic ITP and it is likely that they reflect deposition of immune complexes on the surface of the platelet. Raised concentrations of immune complexes are commonly found in patients with HIV disease, and interestingly, the homosexual control patients with normal platelet counts had concentrations of plateletassociated IgG and complement which were significantly higher than those of non-homosexual controls, suggesting that immune complex deposition on platelets may occur without large scale platelet destruction.

A true antiplatelet autoantibody, however, may coexist with immune complexes on the surface of the platelet. Strickler et al reported platelet membrane antibody in homosexual patients with ITP with reactivity against a 25000 molecular weight platelet membrane antigen, suggesting the presence of a $7 \mathrm{~S}$ platelet antibody..$^{13}$

Furthermore, Van der Lelie eluted platelet bound immunoglobulin from his patients with HIV related disease that was shown to bind to normal platelets, indicating the presence of a specific platelet autoan- 
tibody. ${ }^{6}$ The autoantibody is probably directed against an uncharacterised glycoprotein on the platelet surface. Thus it differs from the autoantibody in classic ITP which is commonly directed against the platelet membrane glycoprotein IIb/IIIa complex.

Karpatkin discussed the intriguing possibility of the presence of "anti-antibodies" in the serum of homosexual patients with ITP. ${ }^{14}$ Anti-F $\left(\mathrm{ab}^{\prime}\right)_{2}$ antibodies have been shown in the IgG fraction of these patients' immunoglobulin with activity against autologous, homologous, and normal control $\mathrm{F}\left(\mathrm{ab}^{\prime}\right)_{2}$ fragments. Some of the immune complexes deposited on the platelets in homosexuals with ITP may be composed of IgG anti-F( $\left(\mathrm{ab}^{\prime}\right)_{2}$ complexes. Karpatkin suggested that these $F\left(a b^{\prime}\right)_{2}$ antibodies might represent anti-idiotype antibodies against HIV neutralising antibody.

Interestingly, Cohen et al described the presence of the lupus anticoagulant and anticardiolipin antibodies in patients with HIV infection. ${ }^{15}$ Both are correlated with thrombocytopenia in systemic lupus erythematosus, and anticardiolipin antibodies have also been found in patients with immune thrombocytopenia without lupus. ${ }^{16}$ The presence of the lupus anticoagulant and anticardiolipin antibodies may play a part in the thrombocytopenia associated with HIV disease.

Treatment of immune thrombocytopenia in HIV disease has been discussed elsewhere. ${ }^{17-21}$ Although treatment with prednisolone is effective in most patients, the effect is usually reversed when the drug is withdrawn and it is potentially hazardous in patients at risk from infection. Similarly, though removal of the spleen will achieve a lasting remission in a high percentage of cases, it is as yet unclear as to whether it hastens or promotes the development of AIDS in HIV antibody positive patients. Intravenous immunoglobulin often produces a good rise in platelet count which, though temporary, might permit an invasive investigation such as lymph node biopsy to be performed or might be of value during a bleeding episode. Other treatments, such as danazol, vincristine, and anti-D immunoglobulin, ${ }^{1820223}$ have not been of great value though one or two patients have shown a response. Interestingly, Gottlieb reported an increase in platelet count in a patient on AZT with AIDSrelated thrombocytopenia. ${ }^{24}$ At this hospital we have seen 10 patients with thrombocytopenia improve their platelet count on AZT, though in five this improvement was only temporary. We also noted, however, that in five other HIV antibody positive thrombocytopenic patients the platelet count fell further while on the drug.

Recent reports of the use of $\alpha$-interferon ${ }^{2526}$ suggest that this agent might be of value in severe AIDSrelated ITP.

\section{Bone marrow changes}

Although bone marrow changes are often seen in HIV disease, there do not seem to be specific abnormalities-rather the marrow is a target for the combined effects of infection, drugs, and chronic disease. Several findings of interest, however, have been reported in HIV patients which may be typical, if not specific. One finding is the difficulty sometimes experienced in aspirating marrow, and probably related to this, a discrepancy between the cellularity of the aspirate and the trephine biopsy specimen. Spivak reported increased marrow reticulin in 10 of 12 patients studied ${ }^{4}$ as did Geller in 28 of 36 biopsy specimens, ${ }^{27}$ and this may be the reason for difficulty in marrow aspiration.

The cellularity of the marrow on trephine biopsy is usually normal or increased, ${ }^{82}$ though Treacy $^{1}$ and Namiki $^{29}$ report hypocellularity in a proportion of their cases and 12 of 60 bone marrows recently reviewed at this hospital were hypocellular. Dysplastic changes are common in erythroid and granulocytic lines. $^{829}$

Megaloblastic changes in the red cell series are seen in a few cases and may reflect myelodysplastic changes or concurrent treatment with co-trimoxazole. Red cell hypoplasia is an interesting observation in some cases and may be related to disseminated MAI infection. "

Several workers have reported increased numbers of lymphocytes in the marrows of patients with AIDS, sometimes in the form of lymphoid aggregates on biopsy $^{482-30}$ and may represent a reaction to viral insult by herpes simplex, cytomegalovirus (CMV), or Epstein-Barr virus (EBV). Granulomas are sometimes observed in the marrow ${ }^{89} 30$ and may be associated with histochemical evidence of acid fast bacilli or fungal organisms.

The increased numbers of plasma cells and histiocytes often observed ${ }^{428}$ is likely to be secondary to repeated infections. Some marrows show striking haemophagocytosis and this has previously been described in CMV and herpes simplex infection ${ }^{41}$ and in tuberculosis ${ }^{32}$ and histoplasmosis. ${ }^{33}$

The reticuloendothelial iron block seen in many patients with AIDS is a reflection of their clinical condition, with repeated episodes of infection caused by opportunistic organisms.

Bone marrow aspirates are often requested clinically to exclude Kaposi's sarcoma or non-Hodgkin's lymphoma, or for microbiological staining and culture. In disseminated infection MAI may be cultured from bone marrow aspirates and is associated with anaemia and red cell hypoplasia. ${ }^{\text {" Cryptococci and }}$ histoplasma have also been shown in marrow aspirates $^{293}$ and Hayman reported a patient with AIDS in whom Pneumocystis carinii organisms were 
shown in the bone marrow biopsy specimen. ${ }^{35}$ We have recently seen a patient with AIDS who had extensive marrow disease with Leishmania.

The bone marrow cellularity in the patient infected with HIV does not always correlate with the peripheral blood findings. The commonly seen pancytopenia is often associated with an active, even hyperactive marrow, suggesting either dysmyelopoiesis or increased peripheral utilisation of blood cells. As previously discussed, immune mechanisms have been implicated in many cases of thrombocytopenia and in some cases of neutropenia.

It seems likely that although the bone marrow is obviously an affected organ in HIV disease, it is the target of many insults-drugs, opportunistic infections, and even the HIV retrovirus itself.

\section{Lymphoma in HIV disease}

Patients with HIV disease have an increased incidence of diffuse non-Hodgkin's lymphoma. This is often high grade and almost always of B cell origin. ${ }^{36}{ }^{37} \mathrm{~A}$ high incidence of extranodal and primary brain disease is observed, these features being similar to those seen in lymphomas developing in patients with congenital immunodeficiency such as Wiskott-Aldrich syndrome or ataxia telangiectasia, or in iatrogenic immunodeficiency states such as post-renal transplant. Although patients with non-Hodgkin's lymphoma associated with HIV infection may respond initially to combination chemotherapy, the relapse rate is high and the overall prognosis poor. Patients with other manifestations of AIDS at the time of development of non-Hodgkin's lymphoma seem to fare much worse. ${ }^{36}$ The malignant lymphoma probably arises as a monoclonal outgrowth from a pool of proliferating $B$ lymphocytes ${ }^{36}$ which have been stimulated by the Epstein-Barr virus ${ }^{38}$ and possibly also by other infective agents such as CMV.

We recently treated a patient with antibodies to HIV who developed acute lymphoblastic leukaemia of B cell origin (B-ALL), ${ }^{39}$ and Rossi $^{40}$ has reported a similar case. It seems likely that B-ALL in addition to non-Hodgkin's lymphoma of B cell origin is a manifestation of AIDS in a patient with anti-HIV antibodies.

Hodgkin's disease has been reported in patients at risk for AIDS by several workers, ${ }^{41-3}$ though as yet the incidence is unclear.

Undoubtedly over the next few years we shall see many more patients with haematological abnormalities related to HIV disease, either directly by the retrovirus itself or indirectly as a complication of infection or treatment. The complex multisystem pathology in patients with AIDS is reflected in the almost universal finding of changes in the blood picture. The study of patients with less advanced disease might enable us to elucidate the cause of the haematological changes and to assess their clinical importance.

\section{References}

1 Treacy M, Lai L, Costello C, Clark A. Peripheral blood and bone marrow abnormalities in patients with HIV related disease. $\mathrm{Br} J$ Haematol 1987;65:289-94.

2 Pinching AJ. The acquired immune deficiency syndrome. Clin Exp Immunol 1984;56:1-13.

3 HIV disease and bone marrow changes: a study of 10 cases. Mir N, Costello C, Lukit J, Lindley R. Eur J Haematol 1988;(in press).

4 Spivak JL, Bender BS, Quinn TC. Haematologic abnormalities in the acquired immune deficiency syndrome. Am J Med 1984;77:224-8.

5 Murphy MF, Metcalfe $\mathrm{P}$, Waters $\mathrm{AH}$, et al. Incidence and mechanism of neutropenia and thrombocytopenia in patients with human immuno deficiency virus infection. Br J Haematol 1987;66:337-40.

6 van der Lelie J, Lange JMA, Vos JJE, van Dalen CM, Danner S A, von dem Borne AEG. Autoimmunity against blood cells in human immunodeficiency virus (HIV) infection. Br J Haematol 1987;67:109-14.

7 Leiderman IZ, Greenberg ML, Adelsberg BR, Siegal FP. A glycoprotein inhibitor of in vitro granulopoiesis associated with AIDS. Blood 1987;70:1267-72.

8 Zon LI, Arkin C, Groopman JE. Haematological manifestations of the human immune deficiency virus (HIV). Br J Haematol 1987;66:251-6.

9 Richman DD, Fischl M, Grieg MH et al. The toxicity of azidothymidine (AZT) in the treatment of patients with AIDS and AIDS-related complex. $N$ Engl $J$ Med 1987;317:192-7.

10 Costello C, Mir N, Luckit J. The blood transfusion service and zidovudine treatment for AIDS. Br Med J 1987;295:1486.

11 Gardener TD, Flanagan P, Dryden MS, Costello C, Shanson DC, Gazzard BG. Disseminated mycobacterium aviumintracellulare (MAI) infection and red cell hypoplasia in patients with the acquired immune deficiency syndrome (AIDS). $J$ Infect (in press).

12 Walsh CM, Nardi MA, Karpatkin S. On the mechanism of thrombocytopenic purpura in sexually active homosexual men. N Engl J Med 1984;311:635-9.

13 Strickler RB, Abrams DI, Corash L, Shuman MA. Target platelet antigen in homosexual men with immune thrombocytopenia. $N$ Engl J Med 1985;313:1375-80.

14 Karpatkin S. Immunologic thrombocytopenic purpura in patients at risk for AIDS. Blood Reviews 1987;1:119-25.

15 Cohen AJ, Philips TM, Kessler CM. Circulating coagulation inhibitors in the acquired immune deficiency syndrome. Ann Intern Med 1986;104:175-80.

16 Harris EN, Gharavi AE, Hughes GRV. Antiphospholipid antibodies. Clin Rheum Dis 1985;11:591-609.

17 Costello C, Treacy M, Lai L. Treatment of immune thrombocytopenic purpura in homosexual men. Scand J Haematol 1986;36:507-10.

18 Oksenhendler E, Bierling P, Farcet JP, Rabian C, Seligmann M, Clauvel JP. Response to therapy in 37 patients with HIV-related thrombocytopenic purpura. Br J Haematol 1987;66:491-5.

19 Delfraissy JF, Tertian G, Dreyfus M, Tchernia G. Intravenous gammaglobulin, thrombocytopenia and the acquired immunodeficiency syndrome. Ann Intern Med 1985;103:478.

20 Mintzer DM, Real FX, Jovino L, Krown SE. Treatment of Kaposi's sarcoma and thrombocytopenia with vincristine in patients with acquired immunodeficiency syndrome. Ann Intern Med 1985;102:200-2.

21 Tertian G, Risler N, Le Bras P, et al. Intravenous gammaglobulin treatment for thrombocytopenic purpura in patients with 
human immunodeficiency virus (HIV) infection. Eur $J$ Haematol 1987;39:180-1.

22 Durand JM, Hart JR, Vendot JJ, Weiller PJ, Mongin M. Anti-Rh. (D) immunoglobulin for immune thrombocytopenic purpura. Lancet 1986;ii:50.

23 Biniek R, Malessa M, Brockmeyer NH, Luboldt W. Anti-Rh (D) immunoglobulin for AIDS-related thrombocytopenia. Lancet 1986;ii:627.

24 Gottlieb MS, Wolfe PR, Chafey S. Case report: response of AIDS related thrombocytopenia to intravenous and oral azidothymidine. AIDS Research and Human Retroviruses 1987; 3:109-14.

25 Ellis ME, Neal DR, Leen CLS, Newland AC. Alfa-2a recombinant interferon in HIV associated thrombocytopenia. $\mathrm{Br}$ Med $\mathrm{J}$ 1987;295:1519.

26 Lever AML, Brook MG, Yap I, Thomas HC. Treatment of thrombocytopenia with alfa interferon. Br Med J 1987;295: 1520.

27 Geller SA, Muller R, Greenberg ML. Acquired immunodeficiency syndrome distinctive features of bone marrow biopsies. Arch Pathol Lab Med 1985;109:138-41.

28 Shenoy CM, Lin JL. Bone marrow findings in acquired immunodeficiency syndrome (AIDS). Am J Med Sci 1986;292:372-5.

29 Namiki TS, Boone DC, Meyer PR. A comparison of bone marrow findings in patients with acquired immunodeficiency syndrome (AIDS) and AIDS-related conditions. Haematol Oncol 1987;5:99-106.

30 Castella A, Goxson FS, Mildvan D, Witt DH, Zalusky R. The bone marrow in AIDS. Am J Clin Pathol 1985;84:425-31.

31 Risdall RJ, McKenna RW, Nesbit ME. Virus-associated haemophagocytic syndrome. Cancer 1979;44:993-1002.

32 Chandra P, Chaudhery SA, Rosner P, Kagen M. Transient histiocytosis with striking phagocytosis of platelets. Arch Intern Med 1975;135:989-91.
33 Cooperberg AA, Schwartz J. The diagnosis of disseminated histoplasmosis from marrow aspiration. Ann Intern Med 1964: 61:289-95.

34 Bishburg E, Eng RHK, Smith SM, Kapila R. Yield of bone marrow culture in the diagnosis of infectious diseases in patients with acquired immunodeficiency syndrome. J Clin Microbiol 1986;24:312-14.

35 Heyman MR, Rasmussen P. Pneumocystis carinii involvement of the bone marrow in acquired immunodeficiency syndrome. Am J Clin Pathol 1987;87:780-3.

36 Ziegler JL, Beckstead JA, et al. Non-Hodgkin's lymphoma in 90 homosexual men. Relation to generalised lymphadenopathy and the Acquired Immunodeficiency Syndrome. $N$ Engl J Med 1984;311:565-70.

37 Iochim HL, Cooper MC. Lymphomas of AIDS. Lancet 1986;i:96.

38 Purtilo DT. Epstein-Barr virus induced oncogenesis in immunedeficient individuals. Lancet 1980;i:300-3.

39 Flanagan P, Choudray V, Costello C. HIV associated B-cell ALL. Br J Haematol 1988;(in press).

40 Rossi G, Gorla R, Cadea OP, Stellini R, Marinone G. Acute lymphoblastic leukaemia of B-cell origin in an anti HIV positive intravenous drug abuser. Br J Haematol 1988;68:140-1.

41 Robert NJ, Schneiderman H. Hodgkin's disease and the acquired immunodeficiency syndrome. Ann Intern Med 1984;101:142-3.

42 Ioachim HL, Cooper MC, Hellman GC. Hodgkin's disease and the acquired immunodeficiency syndrome. Ann Intern Med 1984;101:876.

43 Temple JJ, Andes WA. AIDS and Hodgkin's disease. Lancet 1986;ii:454-5.

Requests for reprints to: Dr Christine Costello, Department of Haematology, St Stephen's Hospital, Fulham Road, London SW10 9TH, England. 